\title{
The Crisis Communication Modes of the Manager in China "Downsizing" Events: Multiple Case Studies Based on Content Analysis
}

\author{
Li-Kun WEI ${ }^{1, a^{*}}$, Wei-Zheng CHEN ${ }^{2, b}$ \\ 1Business School of Sichuan University, Jincheng College of Sichuan University in China \\ 2Business School of Sichuan University in China \\ aweilikun2004@126.com, bcharleswchen@163.com
}

Keywords: Downsizing events, Crisis communication, Manager reactions, China context.

\begin{abstract}
Positive and effective communication can reduce the negative impact of the layoffs, but it is lack of empirical research on the field in China. We collected 120 "downsizing" events, from January 2001 to January 2013 in China. Through content analysis and case study, results shows that three main bodies in crisis communication are: top managers, human resources managers and public relations managers; but exist the following problems need to be perfect and improve: (1)Manager's behavior contrary to good faith in crisis communication such as lying; (2) Some behavior deviated from the manager's duties; (3)Lack of crisis pre-arranged planning and process; (4)Response to the crisis event is lack of consistency; (5)The strategic value of the HRM department is not stand out. This paper reveals the present situation of Chinese layoff communication for the first time, laid the groundwork for future research and management practices.
\end{abstract}

\section{Introduction}

In the process, organization downsizing mainly involve the planners or principal, executive or agent, victims and survivors. The first two roles are usually regarded as the managers; the latter two are in the charge of managers. Layoff communication refers to a behavior by means of which an enterprise, after realizing the importance of communication in downsizing process, actively takes a positive communication strategy to fully communicate with the managers at all levels as well as the victims and survivors to reduce the adverse impact of staff reduction.

Honest, public and frequent information can help avoid rumors; in the case of information failure, staff will fill in the information blank with their assumptions and rumors, and these assumptions and rumors are often based on the worst-case scenario (Caudron,1996). Once a redundancy begins to be enforced, a change will take place to the organizational environment, at which time the management should avoid falling into the trap of "returning to normal", because communication will affect the downsizing effect after a series of changes caused by redundancy. After the end of downsizing, the enterprise concerned will enter a "maintenance" status quickly, in which all its previous efforts and care for the staff will form a new organizational culture. The organization has got ready for the challenge, and the employees need to understand the new management vision and direction, such as financial objective and competitive environment. Communication is particularly important in this process.

Chinese scholars have made in-depth studies on the importance of communication in downsizing process. For instance, Cao Dayou and Zhao Shuming (2004) argue that internal and external communication is the most important and complex management activity in downsizing process, which has a direct influence on staff's psychological state and organizational atmosphere, so in downsizing practice, enterprises always pay great attention to the design of a communication plan and activity with sights on the scientificity and rationality, so as to minimize the negative effects of staff reduction. Liu Tiemin and Li Xue (2008) carried out an empirical research, finding that the most unsatisfactory factors or the most serious problems existing in downsizing process include layoff communication, layoff fairness, layoff decision, post-layoff organization reshaping, laid-off staff management, etc., among which communication dissatisfaction ranks first; Lin Jingxin (2009) holds 
that the most important means for crisis prevention in downsizing process lies in the communication and dealing with three parties: internal staff in emotional counseling, media in public opinion monitoring and communication, and competent authorities in effective communication.

Downsizing practice is a complex system, around the downsizing strategy, based on the institutional basis as layoffs standard, procedure and compensation, as layoff modes, communication and interpersonal treatment for contingency characteristics (Wei Likun \& Chen Weizheng, 2015).

Sweeney (2011) considered that downsizing is a balancing action essential: managing the legacy of the organization, its reputation and its ongoing business performance, and managers should focus on five tasks in turn: retention of corporate reputation; manage communications; manage the actual closure; manage investment in employees; manage continuity of operations.

Because downsizing will be led to negative effects on the organization and staff, layoffs managers often face a greater risk management, whose task in crisis communication mainly manifests in:

\section{Maintaining Organizational Reputation}

Downsizing will seriously affect the corporate image and reputation. When organization layoffs decision-making process was unfair, victims would not be willing to recommend former employer to others (Konovsky \& Folger,1991). On the research on the influence of downsizing to corporate social performance reputation showed: regardless of the success of layoffs and downsizing, the company's social performance reputation will be affected by different degree of negative; between the high financial performance and social performance reputation, company managers are more willing to choose the former, and give up the latter(Zyglidopoulos,2004). Kammeyer Mueller and Hui Liao (2006) found that cuts labor will reduce the attraction of the job seekers, however, if the company provide employees with the aid of downsizing and adequate communication, employers attractive will fairly and no layoffs of company.

\section{Keeping Organizational Justice}

Managers are often the decision makers and executors of the redundancy schemes, the transmitters to layoffs information, is the main impact of interactive justice in layoffs. Byrne (1999) argue that managers often develop and use their own decision-making process, organizations also have often been personified, she divided organizational justice into four dimensions: organization procedural justice, organization interactive justice, managers procedural justice and managers interactive justice.

Gilliland et al.(2003) considered that managers' personal tendency (such as personality, management style and experience) and the constraint conditions (such as: the time limit for the layoffs, and shortage of management personnel), and the manager's psychological cost (such as: employee alienation and transferring blame or shoot) is an important factor decided to fair treatment, in the process of layoffs, the managers of the above characteristics will impact on information sharing and interpersonal sensitivity.

\section{Facilitating Organization Innovation}

Downsizing as a way of resource optimization, usually break the existing power relations, therefore face greater resistance to change. Top management is the enterprise's strategic decision makers and radical reformers, as "agents of change", they tend to take the downsizing as organizational transformation, strategic oriented, focus on efficiency of layoffs and the organization's financial performance indicators. As a result, once decided to implement downsizing, managers must have a good reason and clear objectives for downsizing, through the planning, publicity and vision, decisive action, to achieve the business goals.

\section{Recovering Staff Morale}

Downsizing often threat to employee's job stability and break the management trust. When employees consider layoffs behavior invalid or injustice, their job security is reduced and lose confidence for future development of enterprise. Survivors become risk averse, short-term compromises, conservative and loss the ability to innovate. Low morale also tends to spill over to 
other areas and activities in the corporation. Motivation generally is affected. Productivity tends to suffer and an overall climate of discontent takes over in the corporation. Other side effects seem to accompany the decline in morale. They include a sense of loss and alienation, a sense of chaos, and a strong sense of uncertainty. These are particularly unwelcome when they are found in middle managers, since they tend to serve as examples and to transfer their feelings to their subordinates.(Makawatsakul,2003)

Sanghamitra et al. (2005) thinks that tasks after layoffs include: rebuild the survivors psychological contract; providing support and opportunities to peoples try to new ability; promote the adjustment of employees mentality; Supervise and manage the influence of downsizing on individual and organization; To develop a continuous inspection and organization management concept of culture, make change a systematic and continuous process rather than a one-off move; create a collective learning culture, the error as a learning opportunity, experiences and lessons from the mistakes will be used for future management practices.

Compared with western developed countries, China's enterprise downsizing management is immaturity. The performance of layoffs managers has not yet been revealed systematically. Theory explore need to focus on common features and differentiation in crisis communication of Chinese layoffs managers, also need to reflect the outstanding management problems, this paper is based on such views to exploratory analysis.

\section{Method}

\section{Case Data Collection}

Since the issue of staff reduction is excessively "sensitive" and it is very hard to get real and effective primary data through corporate research and interview, the scope of case study is defined as follows in this research: make a multi-case study with "downsizing events" as a mainline; take samples from January, 2001 to January, 2013, to highlight the features of Chinese enterprises' current practice in downsizing; case data comes from the formally released news reports, the data of each case comes from at least 3 media; a cross-case cluster analysis is made on all the cases that meet the above conditions. 120 cases are obtained after collection and collation, with a case library established for Chinese enterprises’ practice in staff reduction.

\section{Coding}

A quantitative semantic content analysis is carried out on the case data with sentence as the minimum unit of semantic analysis; then, the general facts and themes presented by the case data are encoded.

Open coding is a process in which initial data is conceptualized, requiring that a researcher should remove his personal prejudice and theory set before encoding the data according to its attribute and theme. In this step, this research extracted the theme presented by layoff communication behavior for enterprise top management, PR manager and HR manager, the concrete content being shown in table1.

The focus of axial coding is to explore the relationship between various themes, categories and semantic meanings. This research linked the themes presented by staff behavior together by means of such 4 behavior patterns as "maintaining organizational reputation, keeping organizational justice, facilitating organization innovation and recovering staff morale”, the result being shown in table 2 .

To ensure coding validity, this research invited 3 human resource managers and 3 postgraduates majoring in enterprise management to finish coding, and all of the Holsti reliability coefficients exceeded 0.80, an acceptable level; in this research, an in-depth document research was carried out to lay a good theoretical foundation for code design. The coder had an accurate understanding of code definition due to the ex-period training and pre-coding, who carried out operations in strict accordance with the procedures in the coding process, so a high content validity was ensured. 


\section{Results}

To explore the communication behavior trend of Chinese layoff managers, the paper carried out a further frequency statistics (as is shown in Tab.1), finding that in the 120 cases, 43.3\% of the enterprise senior managers appeared, $64.2 \%$ of the PR managers appeared, and $22.5 \%$ of the human resource managers appeared, that the senior managers had the most abundant crisis communication behaviors — 11 kinds, the PR managers had 8 kinds of crisis communication behaviors, and the human resource managers had 6 kinds of crisis communication behaviors, and that "denial of downsizing" and "explanation of downsizing" became a behavior pattern commonly adopted by the three kinds of managers. A further analysis showed that Chinese layoff managers' crisis communication behavior had distinctive time features and localized connotations, and there was a very conspicuous contradiction between "fairness" and "efficiency" in layoff management, concretely manifested as table 1 :

\begin{tabular}{|c|c|c|c|c|c|}
\hline \multirow{15}{*}{$\begin{array}{l}\text { Senior } \\
\text { Manager }\end{array}$} & Behavior & $\%$ & \multirow{9}{*}{$\begin{array}{c}\text { PR } \\
\text { Manager }\end{array}$} & Behavior & $\%$ \\
\hline & \multirow{14}{*}{$\begin{array}{l}\text { Denial } \\
\text { Explain } \\
\text { Inconsistent } \\
\text { Admit } \\
\text { Support } \\
\text { Guilt apology } \\
\text { Promote vision } \\
\text { Promise not to cut } \\
\text { Break a promise } \\
\text { Against layoffs } \\
\text { Keep silent }\end{array}$} & 27 & & Deny or partly denied & 51.9 \\
\hline & & 21.2 & & Explain & 48 \\
\hline & & 21.2 & & Admit or some admit & 23.4 \\
\hline & & 19.2 & & Make a statement & 13 \\
\hline & & 19.2 & & No comment & 9 \\
\hline & & 13.4 & & Apology or acknowledgement & 5.1 \\
\hline & & 9.7 & & Reassure compromise & 5.1 \\
\hline & & 7.6 & & Block or threat & 2.6 \\
\hline & & 3.9 & & Denial & 28 \\
\hline & & 3.9 & & Explain & 28 \\
\hline & & 1.8 & HR & Recruitment or restart & 25.8 \\
\hline & & & Manager & Emphasis on the legitimacy & 18.7 \\
\hline & & & & Redress & 14.7 \\
\hline & & & & Careers guidance & 11.1 \\
\hline
\end{tabular}

Table 1: frequency analysis for layoffs managers crisis communication behaviour

\section{The Senior Managers' Crisis Communication Behavior in the Downsizing Events}

Among the 11 communication behaviors of the senior managers, “denial of downsizing” appeared the most frequently (27\%), and "silence keeping” appeared the least frequently (1.8\%), as follows:

\section{Denial of Downsizing, Antilogy and Inconsistency Between Words and Deeds}

Although there is conclusive evidence that a downsizing action was already taken, but the senior managers denied it or regarded it as a normal personnel adjustment, non-economic layoff or non-active layoff in $27 \%$ of the cases; $21.2 \%$ of the senior managers acted at variance with what they said and denied layoffs but made an inconsistent explanation to layoffs later.

\section{Support for Downsizing and Vision Propagating}

$19.2 \%$ of the senior managers provided public support for layoffs, such as asserting that "the organizational integration and optimization is a normal organizational optimization and adjustment."; $9.7 \%$ of the senior managers propagated a vision, such as "to help customers save money and lead a better life, Wal-Mart must further improve the corporate efficiency."

\section{Acknowledgement and Explanation}

$19.2 \%$ of the senior managers confirmed the rumor of downsizing, such as "the news of downsizing was already released in the financial report published in the first quarter of this year, and it is unnecessary for the outside world to pay excessive attention"; $21.2 \%$ of the senior managers made an explanation to the rumor. 


\section{Promise and Promise Breaking}

$7.6 \%$ of the senior managers promised not to reduce the staff in public, however, $3.9 \%$ of the senior managers broke the promise. For example, they promised not to reduce the staff, but they announced layoffs in an open letter.

\section{Self-Reproach and Apology}

$13.4 \%$ of the senior managers felt sorry for downsizing behavior."As a former CEO that took office ten years ago, I still feel guilty for staff reduction”, "we will show care and respect for each staff affected in this plan."

\section{Opposition against Downsizing and Confrontation with the Superior}

$3.9 \%$ of the senior managers spoke out against downsizing and confronted with the superior. For instance, the senior managers of Shanghai Lianyou and ku6 left the company or were removed from office after a downsizing event occurred in 2010 and 2011 respectively.

\section{PR Managers’ Crisis Communication Patterns in Downsizing Events}

Among PR managers' 8 kinds of communication behaviors, "denial or partial denial of layoff” appeared the most frequently (51.9\%), and "threat-based blackout" appeared the least frequently (2.6\%), concretely manifested as:

\section{No Response and Denial Or Partial Denial of Layoff}

In the face of a rumor and a question raised by media, $9 \%$ of the enterprises chose not to respond; $51.9 \%$ of the enterprises denied or partially denied downsizing; $23.4 \%$ of the enterprises chose to admit or partially admit downsizing; the above shows that Chinese enterprises know much about the adverse impact of downsizing and thus keep downsizing information dark. To weaken the impact of downsizing, the PR managers often describe downsizing with such words containing a strategic vision as talent optimization, organizational redesign and business innovation, etc. In addition, there is a strict approval and operational procedure for economic downsizing stipulated in Chinese law. To avoid legal liabilities, some of the enterprises surveyed usually described an economic downsizing as a small-scale downsizing or normal personnel adjustment. "Integrity" is the basis for an enterprise's survival. When an enterprise talks insincerely and "lies" about the problem of layoffs, its reputation will come to a greater harm.

\section{Declaration and Explanation}

For a rumor of downsizing, $13 \%$ of the enterprises issued a declaration in public to clarify the fact; $48 \%$ of the enterprises made an explanation to the matter of downsizing. Both declaration and explanation include the following main contents: (1) attribute the responsibility of rumors to the relevant responsible people, and stressed staff's negative behavior, such as "offensive comments posted by dismissed staff on the Internet due to their bad emotions"; (2) explain the cause of downsizing and strive to gain the forgiveness of the society. For instance, "Owing to the impact of the entire household appliances industry, the enterprise has to take a measure to actively transform itself, enhance the added value and improve the operational efficiency.”; (3) emphasize the legitimacy of downsizing, and investigate the rumor-monger or conflict maker for legal liabilities, such as "when a rumor is proved untrue or it is thought someone starts a rumor maliciously"; (4) reduce the redundancy size and describe staff reducing means, including lowliest place elimination and institutional abolishment, as reasonable personnel optimization or adjustment, such as the description that "it is a normal performance appraisal that the last one will be eliminated in each year".

\section{Acknowledging and Apologizing}

$5.1 \%$ of the enterprises expressed gratitude or made an apology to the dismissed staff. "we made this adjustment with a heavy heart, but we wish the staff and all circles understand us"; SAE wrote "a letter of thanks" to the laid-off staff while reducing them in 2008. 


\section{Human Resource Managers’ Crisis Communication Patterns in Downsizing Events}

Among human resource managers' 6 kinds of communication behaviors, "denial of downsizing” and "explanation of downsizing" appeared the most frequently (28\%), and "employment guidance" appeared the least appearance (11.1\%), concretely manifested as:

\section{Denial of Downsizing and Explanation of Downsizing}

As the core department of downsizing, corporate personnel department should speak along the same line with PR department, so it denies the rumor of downsizing in front of media. The concrete methods include: Claim to know nothing by emphasizing that layoff decision is made by the top management; Describe downsizing as something not equivalent to "downsizing"; Refuse to make downsizing information public; Deny downsizing scale and post-layoff staff remuneration.

\section{Emphasis on the Legitimacy of Downsizing}

$18.7 \%$ of the enterprises stressed the legitimacy of downsizing in the following ways: Stress the standardization of enterprise qualification and management; Emphasize the legitimacy of staff reduction; Emphasize the legitimacy of downsizing reason; Emphasize the legitimacy of downsizing flow.

\section{Recruitment and Reemployment}

As an renewal and public relation means, $25.8 \%$ of the enterprises enhanced campus recruitment while reducing staff. In contrast, the newly recruited fresh graduates are often the first to be dismissed. Besides, some enterprise promises to reemploy the dismissed staff, "If the company develops better in the future and needs to recruit staff, we will consider first choosing the staff dismissed this time."

\section{Assistance, Settlement and Compensation}

Some enterprises' human resource department provided employment assistance for the dismissed staff, such as gathering employment information from related industries, and helping write a resume; But $14.7 \%$ of the enterprises adopted a corresponding measure to cope with a dispute on downsizing.

\section{Discussion}

\section{The Classification of Layoffs Managers’ Crisis Communication Behaviors}

First, mutually opposite behavior patterns, such as "admit or denial downsizing”, are classified and combined according to management ethics and the ethical standards for professional managers, and there are 6 sets of opposite behaviors in this research; second, the same behavior patterns of the managers at different levels are classified and combined; finally, the behavior patterns that 6 people agree to put under the same type of managerial roles are preserved, and the concrete contents are shown in table 2:

\begin{tabular}{|c|c|c|c|}
\hline $\begin{array}{c}\text { Maintaining } \\
\text { Organizational } \\
\text { Reputation }\end{array}$ & Keeping Organizational Justice & $\begin{array}{c}\text { Facilitating } \\
\text { Organization } \\
\text { Innovation }\end{array}$ & Recovering Staff Morale \\
\hline Explain & Guilty & Promote vision & Promise not to cut \\
Make a statement & Apology & Admit that layoffs & Break a promise \\
Blocking information & Acknowledge & Denied & Re-employ \\
& Respond or no comment & Support & Commitment to restart \\
& Emphasis on the legitimacy & Against layoffs & Careers guidance \\
& & Discharge & Reconciliation \\
& & Recruitment & Redress \\
\hline
\end{tabular}

Table 2: the classification of layoffs managers' crisis communication behaviors 


\section{Layoffs Managers’ Crisis Communication Barriers and Management Defects}

A further research indicates that Chinese downsizing managers have certain crisis PR consciousness while handling a “downsizing” event, but they don't play a clear role. The downsizing managers at all levels are troubled by the following communication barriers and management faults: (1) This is first manifested as that the downsizing managers at all levels violate corporate credit more or less, such as telling a lie, denying downsizing and breaking the promise, etc. While the downsizing managers explain the legitimacy and rationality of downsizing, their legal consciousness and business ethics are questioned; (2) the downsizing managers' actual behavior deviates from their management function. For example, the senior managers should be an advocate and a strong strategic promoter of a downsizing program, but some senior managers openly "oppose downsizing". In the face of a rumor, the public relations officials, however, refuse to respond and even block the passage of information, so that a "downsizing" scandal continues, with public trust lost; (3) Senior managers, PR managers and human resource managers regard a "downsizing event” as an emergency, and have no consciousness to prepare an emergency plan or standard procedure in advance, so they can't divide the work clearly with clear responsibilities, but just mutually make excuses and dispute over trifles, and thus they can't act in concert; (4) although Chinese enterprises tend to label downsizing with a strategic change, from a perspective of strategy and operation, two role behavior orientations, the managers at all levels don't have the same understanding of the strategic intent of downsizing. In downsizing process, human resource department doesn't make an outstanding contribution to strategic values, which also confirms from another side that Chinese enterprises still have a weak foundation for downsizing management, which urgently needs to be improved.

\section{References}

[1] S.Caudron, Teach downsizing survivors how to thrive, Personnel Journal. 75 (1)(1996)38-41.

[2] Cao Dayou and Zhao Shuming, Analysis of management behavior of transformational layoffs in Chinese, Foreign Economics \& Management. 5 (2004) 17-20.

[3] Liu Tiemin and Li Xue, Enterprise layoffs empirical analysis and suggestion of problem in Chinese, Enterpriser World.1(2008) 116-117.

[4] Lin Jingxin, Enterprise layoffs crisis communication management in Chinese, Chinese small and medium-sized enterprises.2(2009)104-106.

[5] Wei Likun and Chen Weizheng,The Key Management Elements and Rethink of Downsizing Management Practice in China in Chinese, Economic Management.37(2015)65-74.

[6] M. Sweeney, Managing Downsizing: Key Considerations, http://www.som.cranfield.ac.uk/som/p16640/Think-Cranfield/2011/August-2011/Managing-Downs izing. 08 (2011).

[7] M. Konovsky and R. Folger, The effects of procedures, social accounts, and benefits level on victims’ reactions to layoffs, Journal of Applied Social Psychology. 21(1991)630-650.

[8] S.C.Zyglidopoulos, The impact of downsizing on the corporate reputation for social performance, Journal of Public Affairs. 4(2004)11-25.

[9] J.Kammeyer-Mueller and Hui Liao, Job-seeker attraction: examining job seekers' reactions to firm workforce-reduction policies, Human resource management. winter 45(4)(2006) 585-603. 
[10]Z.S.Byrne, How do procedural and interactional justice influence multiple levels of organizational outcomes?.Symposium presentation at the 14th annual conference of the Society of Industrial and Organizational Psychology. Atlanta ,GA. 1999.

[11]S.W.Gilliland and D.H. Schepers, Why we do the things we do: a discussion and analysis of determinants of just treatment in layoff implementation decisions, Human Resource Management Review. 13(2003)59-83.

[12] N.Makawatsakul and B. H.Kleiner, The effect of downsizing on morale and attrition, Management Research News. 26(2/3/4)(2003)52 - 62.

[13]B.Sanghamitra and C. Leena, Organizational Downsizing from Concepts to practices, Vikalpa.30(2005)65-78. 